\title{
Faculty Grassroots Leadership in Science Education Reform: Considerations for Institutional Change, Culture, and Context
}

\author{
David B. May ${ }^{1}$, Danielle Susskind ${ }^{2}$, Nancy S. Shapiro ${ }^{1}$ \\ ${ }^{1}$ Office of Academic Affairs, University System of Maryland, Adelphi, USA \\ ${ }^{2}$ Division of Academic Policy, Maryland State Department of Education, Baltimore, USA \\ Email: dmay@usmd.edu
}

Received May 29 ${ }^{\text {th }}$, 2013; revised June $28^{\text {th }}$, 2013; accepted July $5^{\text {th }}, 2013$

Copyright (C 2013 David B. May et al. This is an open access article distributed under the Creative Commons Attribution License, which permits unrestricted use, distribution, and reproduction in any medium, provided the original work is properly cited.

\begin{abstract}
A multi-institution project was implemented with the goal of improving science education through redesigned courses, inquiry-oriented pedagogy, and outreach to public schools. We examined the nature of faculty grassroots leadership in science education reform in the four main higher-education partners of the project: a community college, a master's level university, and two different research universities. The main focus of the study was the interplay and role of top-down leaders in positions of authority (typically administrators) versus grassroots leadership among faculty and how these two converge and interplay to create organizational change. The convergence of bottom-up and top-down leadership is affected by institutional culture and context. Cross-comparative findings from the four cases are presented, including the context for change in each case, the role of administrative leadership on each campus, factors that either facilitated or hindered the emergence of faculty grassroots leadership, and the institutionalization and sustainability of these reforms. We then address the broader implications of the study with respect to understanding how grassroots leadership and traditional forms of authority and leadership can complement each other and facilitate organizational change. We contend that faculty grassroots leadership emerges on different campuses when there is sensitivity to the contextual differences. In particular, some attention needs to be given to the campus culture and the nature of faculty interactions at that site. The context for change at each institution and the role of administrative leadership and support shaped the conditions under which faculty grassroots leadership had emerged and, ultimately, the degree to which it was sustained over time. In addition, the faculty ownership of this project was essential to its success because, ultimately, the faculty needed to embrace the goals of curricular redesign and inquiry-oriented pedagogy for the desired institutional changes to be sustained.
\end{abstract}

Keywords: Course Reform; Faculty Engagement; Leadership; Science Teaching; Higher Education

\section{Introduction}

This article presents four case studies of faculty grassroots leadership in a science education partnership involving multiple higher education institutions and a K-12 school system in which top down and grassroots leaders work in concert to create change, a relatively unexplored area. While we know a great deal about top down change efforts, we know much less about top down efforts merging with grassroots efforts within institutions and organizations. Grassroots leadership efforts have a long history, but have not been documented or well understood. For example, higher education faculty have had a long history of grassroots involvement in educational reform efforts, including the alignment and review of courses and curricula (both at the K-12 and college levels); the development and delivery of workshops, institutes, and courses for K-12 teachers to increase their content knowledge and pedagogical skills; participation in learning communities with $\mathrm{K}-12$ teachers; and direct service as a content resource or teaching mentor in $\mathrm{K}-12$

*This research was supported by National Science Foundation Grant DUE 0227325 awarded to Nancy Shapiro. schools (Greenberg, 1991; Wallace, 1993; Timpane \& White, 1998; Verbeke \& Richards, 2001; Wiseman \& Knight, 2003; Zhang et al., 2007). Most prior research suggests that grassroots leadership among faculty is often thwarted by institutional culture and existing rewards structures (Frank \& Shapiro, 2007). So while grassroots leadership can and does happen, it is uncommon because of existing institutional structures. Many have suggested we need research about how grassroots leadership can be encouraged and what role top down leaders can play.

This article begins with a review of the research and literature on change in higher education which suggests why grassroots leadership is so important, the ways that top down leaders might support such leadership, and the role of institutional culture and change processes. It continues with an overview of the research methodology for the study and the presentation of four cases of faculty grassroots leadership from a multi-institutional partnership-one occurring at a community college, one occurring at a master's level university, and the remaining two occurring at two different research universities. The cross-comparative findings from the four cases are then discussed, including the context for change in each case, the role of admin- 
istrative leadership on each campus, factors that either facilitated or hindered the emergence of faculty grassroots leadership, and the institutionalization and sustainability of these reforms. Finally, the conclusion addresses the broader implications of the study with respect to faculty grassroots leadership theory building and practice.

\section{Higher Education Change in Context}

This section reviews literature related to the authors' main assumptions about change when developing the research study: 1) Change in higher education requires more than top down leadership; 2) Grassroots leadership may require support from top down leaders; 3) Institutional culture shapes change processes and leadership; and 4) Change processes may also require change in institutional culture to be sustainable.

\section{Difficulty of Top-Down Leadership Efforts in Higher Education}

As Eckel and Kezar (2003) have observed, top down leadership efforts aimed at change are typically not successful in higher education due to the way that colleges and universities are structured. While traditional management theory and practice in the United States tend to be more top down and emphasize the role that individual leaders and organizational processes play in change, there are limitations to applying such frameworks that do not incorporate the unique cultural perspectives of higher education. Early in the study of higher education, Cohen and March (1974) discovered that college and university environments were "organized anarchies" that were not recaptive to top-down leadership and hierarchy and operate similar to other professional bureaucracies were with defining characteristics as a service mission, professionalism, goal ambiguity, problematic technology, and environmental vulnerability. Weick (1976) likewise identified those higher education institutions as "loosely coupled systems" with complex parts that are tied together frequently and informally rather than along tight linkages or hierarchical lines. Furthermore, Kezar (2001) identified a number of organizational characteristics of colleges and universities that make top down change processes difficult including their multiple power structures, distributed decision-making and authority, shared governance processes, professional and administrative values, and the presence of competing goals and outcomes. Such analyses all reinforce organizational complexities of colleges and universities and the need for distributed leadership to create change.

\section{The Role of Top-Down Leaders}

While the primary focus of this article is on faculty grassroots leaders, who have been the subject of little study, shared leadership models in higher education suggest that top down leaders may still be important to support bottom up leadership. This is particularly important in light of barriers related to faculty roles and reward structures that earlier research suggests may create barriers to faculty practicing grassroots leadership (Frank \& Shapiro, 2007). Change processes in higher education can become protracted when grassroots leaders are distributed in various places across campus, and it often takes a positional leader with some level of authority to unify these efforts (Kezar, 2001). In addition, change efforts at the grassroots level often require top down support in order to be institutionalized, as they typically have broader administrative implications-including enhancements to infrastructure, development of new policies, and increased fiscal and human resources.

This dilemma of blending top down and bottom up leadership is captured by Hearn (2006) in his research on leadership and change that identified one of the major challenges for institutional leaders is balancing external demands for accountability, which often call for executive style leadership, with more traditional processes of shared governance and distributed leadership on college and university campuses. Most academic leaders, including college presidents, have come up through the ranks of the faculty themselves, and therefore understand this unique cultural context of shared governance (Peck, 1983).

\section{The Role of Institutional Culture and Context}

One of the premises of this article is that organizational culture and the context for change in higher education play a significant role in shaping the extent to which faculty leadership in educational partnerships is valued and rewarded. Kezar and Eckel's (2002) study suggested that change processes in higher education are largely shaped by institutional culture. They found that while there are various general tactics or strategies that work to create change in organizations, change strategies in higher education seem to be most successful when they are contextualized for the specific institution. In examining 26 colleges and universities that were involved in varying types of institution-wide change initiatives, Kezar and Eckel found that institutional leaders are more successful when they choose strategies and tactics that are relevant and a fit with the culture. They observed that change strategies that consider institutional mission, history, and values are better positioned to facilitate change because these strategies are more likely to resonate with members of the campus community and be met with less resistance.

Building on Kezar and Eckel, Merton, Froyd, Clark, and Richardson (2004) in their study of curricular change processes in undergraduate engineering education found that organizational culture was a critical variable in understanding these change efforts. Without a clear understanding of institutional culture before launching these curricular change initiatives, they saw faculty leaders struggling with such issues as persuading fellow faculty to use the new teaching innovations, gaining the necessary departmental and college level approvals, needing to create new structures to coordinate and sustain the programs over time, and keeping up with collaborative relationships across disciplinary and college boundaries. They observed, "The point is that there was no one strategy, no ideal change model, or no universal process that could be applied to each situation that would guarantee successful adoption of these new curricula" (Merton et al., 2004: p. 2). Rather, faculty members had to understand their institutional context well enough to know what approaches would be most effective, and implement culturally relevant strategies for overcoming obstacles and barriers when they arose. In their study of faculty curricular reforms at a research university, Frost and Teodorescu (2001) even went a step further in their views on culture. They asserted that changes involving the curriculum and the teaching and learning environment should be considered as forms of institutional culture change in and of themselves, as these investments of faculty time and effort serve to enhance and legitimize the value that the institution places on such activities. All these studies collec- 
tively suggest the important role of understanding change in higher education will need to respect and work within the shared governance environment and will be shaped by the institutional culture.

\section{Changing Institutional Culture}

At the same time, neither top down administrative leadership nor faculty grassroots leadership may yield sustainable change or result in the widespread adoption of new ideas or methods unless a cultural shift takes place in tandem with such developments. Gaining support for culture change is a complex process. As classic writers in the field of change management such as Lewin (1951) and Schein (1997) have noted, the culture of the organization must change or shift in such a manner that the desired state replaces the existing state. In applying these perspectives on change management to higher education, Ewell (1997) described institutional change as requiring constant and consistent leadership, a fundamental shift in perspective, individuals and organizations to relearn their roles, and systematic ways to measure progress and guide improvements. Further, Burack and Saltmarsh (2007) posited that in order for institutional changes to turn into institutionalized practices, they must become routine, widespread, legitimized, expected, supported, permanent, and resilient, as opposed to those that are marginalized, occasional, isolated, unaccepted, uncertain, weak, temporary, or at-risk. Likewise, Levine (1980), in examining the innovation process at 14 colleges and universities, stressed that innovation efforts in higher education do not tend to become institutionalized unless such changes are congruent with underlying shifts in culture and therefore consistent with institutional values, norms, and goals.

In addition, it is important to note here that the culture within the science, technology, engineering, and mathematics (STEM) disciplines has been cited as a roadblock to change in such types of reform efforts. STEM faculty themselves have stated that while their institutions may publicly support faculty involvement with K-12 schools and teachers, there are very few incentives for faculty to substantively participate in such activities (Frank \& Shapiro, 2007). The premiere faculty rewards structure in the STEM disciplines is shaped by external funding for scientific research, development, and discovery—work that does not directly contribute to this end is viewed as a deterrent, particularly for tenure-track faculty. Further, K-12 outreach has traditionally been seen as something that faculty in colleges and schools of education should be responsible for, rather than drawing upon a broader base of institutional support and responsibility. This disciplinary lens adds yet another layer of complexity to the process of changing institutional culture, yet it is important to recognize the role and potential impact of the academic disciplines, each of which offers its own forms of faculty rewards and recognition, shapes the professional identity of faculty members, and defines and legitimizes the nature of faculty work. Given the importance of disciplinary differences to change in higher education, it is important to understand the context of change within the STEM disciplines and provide background on this area, which we review next.

\section{Faculty Grassroots Leadership in Education Reform}

Recent alarms about America's global standing and competi- tiveness have resulted in urgent national "calls to action” for developing a better trained workforce, a more scientifically literate citizenry, a stronger research and development infrastructure, and an expanded pipeline of students, educators, and other professionals in the STEM fields. These issues have been well documented in several high-profile reports over the past decade. For example, Rising Above the Gathering Storm, the much acclaimed report from the National Academies (2007), examined trends related to the nation's contribution to the global workforce, and advised that if urgent action were not taken immediately, the United States could expect to lose its advantage as a world leader in science and technology. In addition to such policy-oriented reports that call for STEM reform nationally, there is a growing body of research literature that focuses on change in STEM education and instructional practices on college and university campuses (see Henderson, Beach, Finkelstein, \& Larson, 2008, for a recent synthesis).

Given this national and international context, increased attention has been paid to the role that colleges and universities - and their faculty — should play in strengthening the STEM education system and expanding the STEM pipeline, not just in higher education, but across the entire educational spectrum, including K-12. In response, the federal government has established several incentive programs to help prime the pumpraising the stakes for colleges and universities to participate in STEM education reform efforts. In many of these programs, higher education faculty have been called upon to play an active leadership role-by reforming courses and instruction at the college level, by getting involved in the preparation for future teachers, or by lending their expertise to the professional development of in-service K-12 educators. However, such activities are not traditionally valued as faculty "work" in the academy.

Research universities clearly present one of the more challenging contexts for the emergence of this work, given the clear demands for research and scholarship that dominate the institutional mission and culture. Yet, the landscape is gradually shifting: faculty at many other types of four-year institutions are increasingly held accountable to similar incentive structures that reward faculty work in research universities (see Neave, 1979, for a discussion of the concept of "academic drift" in higher education, the tendency for institutions to imitate other types of institutions - particularly research universities-in order to gain prestige and status). Similarly, community college faculty are frequently called upon to partner with K-12 schools through such activities as providing professional development workshops for teachers or offering content courses for teacher recertification. Even for community college faculty, however, $\mathrm{K}-12$ involvement is not typically included in their academic workload.

Thus, faculty who choose to become involved in these initiatives-who are typically rewarded for research, scholarship, and teaching-are finding more of their time invested in activities that fall outside of the traditional boundaries for faculty work. While it is typically faculty members themselvesthrough the process of peer review for juried publications and tenure and promotion decisions - who determine the value and relative worth of the various strands of activity that define faculty work (Fairweather, 2002), it appears that for the most part, traditional faculty reward structures have not yet been recalibrated to incorporate these emerging roles and responsibilities (O’Meara, 2006). In addition, very little is actually understood 
about the role that faculty play in carrying out this work at the grassroots level, or factors that have served to help or hinder their engagement. By examining this phenomenon in the context of one multi-institution science education partnership, this study seeks to build an emerging understanding of the role of faculty grassroots leaders in such change efforts, as well as the complex interplay between faculty leadership, top down leaders, and institutional culture and context.

\section{Research Methods}

The purpose of this study was to examine the emergence of faculty grassroots leadership in the context of one partnership project. The partnership itself involved approximately 75 STEM faculty across four public higher education institutions (one research university with a Carnegie classification of very high research activity, a second research university with a classification of high research activity, a master's level university, and a community college). The partnership also included two independent STEM research institutes in the state's university system and a large suburban school district enrolling approximately 138,000 students. The primary goal of this partnership was to improve science education at the secondary and college levels by enhancing the quality of the curriculum and instruction through professional development and communities of practice for teachers and faculty that emphasized inquiry science teaching and learning (see Handelsman et al., 2004, for research on inquiry instruction as a best practice in the sciences).

The partnership that was the focus of this study was part of a broader set of projects funded by the United States National Science Foundation (NSF) Math and Science Partnership (MSP) program. By facilitating linkages between colleges and universities and K-12 school districts, MSP grants are designed to engage higher education faculty in areas of vital importance for improving STEM education, including K-12 teacher preparation, K-12 teacher professional development, and STEM curriculum reform at all levels. These partnerships currently involve approximately 150 colleges and universities across the United States, and more than 550 school districts and 3300 individual schools in 30 states and Puerto Rico.

This study was designed as a "post-hoc" case study involving four higher education institutions. It followed the tradition of case study methodologies by considering a phenomenon within its "real-life" context—where the boundaries between phenomenon and context are not always clear-and by drawing upon multiple sources of evidence to examine this phenomenon (Yin, 2002). The authors characterize this particular case study approach as "post-hoc" since it built upon events that had already occurred over a finite period of time (i.e., the duration of the partnership) and drew upon secondary data sources. The data informing this case study were gathered over a period of six years and included a broad range of quantitative and qualitative sources that in some cases were collected by the authors, in some cases by external evaluators, and in other cases by the project participants themselves (i.e., faculty and administrators). In the analysis for the study, the authors considered annual reports; external evaluation reports; culminating site chapters; classroom observations; project artifacts (e.g., syllabi and laboratory manuals for new and revised courses, minutes from meetings); surveys and interviews with project administrators, faculty, and deans; and a project-wide social networking study.
It is important to acknowledge that these data sources were originally collected with broader evaluation purposes in mind that were beyond the immediate scope of this study. The challenge before the authors, then, was to develop and apply a framework that would guide the discovery and analysis of instances where faculty grassroots leadership had taken root over the course of the project. Drawing upon case study methodologies outlined by Yin (2002), this research framework included a series of "within-case" analyses that focused on searching for unique patterns within each of the four institutions in the study, followed by a "cross-case" analysis that allowed for the exploration of common themes as well as points of departure across the four institutions.

For the within-case analysis, the authors initially engaged in inductive coding to allow them to consider each institution's data individually-forming descriptive categories for the data and tracking emerging themes across various data sources. In the initial coding process, the authors made two overarching assumptions. The first assumption was that the nature of the work generated by the partnership (e.g., working with K-12 teachers, inquiry-based course reform) falls outside of expected and rewarded faculty roles and responsibilities, and therefore, taking such initiative could be defined as an act of grassroots leadership. Second, the authors assumed that faculty grassroots leadership could exist as an input or an outcome of the partnership. In some instances, faculty leadership at the grassroots level may have already existed to facilitate the emergence of the partnership work on campus, while in other instances, it may have been the partnership work itself that facilitated the emergence of grassroots leadership.

The authors then moved to a cross-case analysis, which focused on the analysis of emerging patterns, themes, and findings across the four cases to uncover patterns of similarity and dissimilarity that emerged, and to examine factors that appeared to contribute to processes and outcomes across the four settings. It was during this process that the authors moved to a more deductive approach to their analysis of the data-considering the findings and their interpretation in light of the four very different institutional role and missions represented in the case study. Drawing upon the research literature on leadership and organizational change in higher education presented earlier in this paper, this analysis included the extent to which factors and influences such as institutional mission and context, leadership priorities, faculty culture, administrative support, and recognition and reward structures were aligned with faculty grassroots leadership efforts in each setting.

\section{Four Cases of Faculty Grassroots Leadership}

The cases that are presented in this section offer insight into the authors' emerging understanding of faculty grassroots leadership at four different institutions involved in a single science education partnership project. The cases begin with the "Catalyst" (occurring at the community college), continue with the "Sponge" (occurring at the master's level university) and "Magnet" (occurring at one of the research universities), and conclude with the "Pied Piper" (occurring at the other research university). The authors found that in some instances, administrative leaders on campus served as the "activators" who led the charge for change and developed specific strategies for engaging faculty at the grassroots level, while in others, it was faculty leaders already working at the grassroots level that led these 
efforts and moved the change agenda forward (see Kanter, 1988, for a discussion of forms of leadership in organizational innovation, including the role of activators). In addition, a nuanced relationship emerged between administrative leadership and faculty grassroots leadership in each of the four cases, which seemed to be heavily dependent on institutional context and campus priorities. Further analysis of how this played out across different types of institutions in this partnership suggests that faculty grassroots leadership was, in some cases, a starting point for engagement in education reform, and in other cases, an end product of such engagement.

\section{The "Catalyst"}

The first case involves a community college (institution A), where the primary mission of the institution is to prepare students for the workforce or for transfer to a four-year college or university. As a teaching institution that was heavily invested in building the STEM and teacher education pipelines, both the college's priorities and mission were clearly aligned with the broader goals of the MSP partnership. While there was a high degree of "random interest" expressed in MSP partnership activities, however, there was very little direct involvement by STEM faculty at the college, at least initially. Although the MSP grant provided considerable funding to support faculty members to join $\mathrm{K}-12$ teachers in learning communities, the lack of emerging faculty leaders precluded participation in the broader partnership, and the college found that it could not spend the grant funding.

After two years of an essentially dormant partnership at this institution, one of the college's science deans (who also served as the campus liaison for the partnership) decided to try a different approach by recruiting a faculty project leader from outside the college. A retired high school science teacher from the partner school district was soon hired. Quickly assessing the needs and interests of fellow faculty, the new project leader developed and implemented a program centered on teaching and learning seminars and faculty professional development. Through the seminars, participating faculty reported on their progress with designing and implementing inquiry-based curricula in the sciences, while having the opportunity to gain feedback, discuss challenges, and share teaching approaches with their colleagues. Through these new initiatives, the faculty project leader served as a "peer coach" to participating faculty-meeting with them periodically, observing their teaching, and providing feedback and support on the implementation of new inquiry techniques in their courses. Without the intervention of the campus leadership (in this case the science dean) this productive strand of faculty activity would not have developed. The external hire served as a "catalyst" for what emerged as a robust faculty development program that eventually touched almost $70 \%$ of the science faculty at the institution.

This "catalyst" had the time to foster networks across the campus. By bringing faculty from different disciplines together into communities of practice, new faculty leaders began to emerge. For example, faculty in the chemistry department started working together to revise their courses for non-science majors and to experiment with portions of their courses for engineering majors. Here is an example of faculty making a shared commitment to curricular reform that would not have occurred if the faculty members stayed in their traditional silos. Similar activities took hold in the departments of physics, engineering, and geosciences. Later, a more formal faculty learning community emerged at the college, and the emergence of these new, faculty led communities led to new collaborative grant applications which secured additional external funding for their work. There is strong evidence in this case study that the intervention of campus level administrators led to a robust and productive surge of faculty leadership, which was then rewarded by the winning of competitive grant funding. A year after the end of MSP project (and now without a dedicated faculty project leader), these collaborations have continued to grow and evolve. Across the community college, at least 18 STEM faculty members are still directly involved in redesigning courses and curricula as an outgrowth of the MSP project, and these faculty leaders now have both resources (grant funding) and access (through deans) to sustain their work.

This case illustrates that a new project's alignment with institutional mission and priorities may be necessary, but not sufficient, for fostering an environment in which leadership and shared ownership initially emerged among faculty. In interviews with participating faculty, researchers learned that the constraints of high teaching loads precluded them from taking leadership for this project despite their interest and support, in theory, for the project. In this case, it took an external change agent hired by an academic administrator to reframe the parameters of faculty leadership in the project. By hiring the right individual to serve as a "catalyst" for mobilizing faculty at the grassroots level, the college was able to harness faculty commitment and momentum for STEM education reform that otherwise may have remained dissipated across the campus.

\section{The "Sponge"}

The second case comes from a public master's university (institution B) in the partnership that boasts one of the strongest teacher preparation programs in the state, and which, like many successful institutions, is striving for increased prestige and recognition. Campus-based learning communities existed on this campus prior to their involvement in the grant-funded project, and a dedicated group of STEM faculty members interested in innovative teaching and learning models, inquiry instruction, and interdisciplinary collaboration already existed on the campus. The new project drew strength from these faculty leaders, and challenged them to draw additional faculty members into the community. Because these faculty leaders had already prepared the way for faculty learning communities, this institution, unlike the other three case studies, was able to "hit the ground running" when the NSF grant funding became available. Because of this institutional context, the researchers expected to see a rapid expansion of faculty participants across disciplines on this campus.

Project leaders were not disappointed. The faculty learning community nearly doubled in size, and they expanded their reach beyond their departmental boundaries out to other higher education partners and to meetings with high school science teachers. The discussions focused on issues related to science teaching and learning, and faculty collaborated on redesigning their own courses with the intention of increasing inquiry and improving student learning, interest, and attitudes. Participating faculty eventually redesigned seven existing courses and created three entirely new inquiry-based courses in science. At the end of the funding period, most of the faculty indicated a desire to continue the learning community, and to expand their efforts 
into new areas. For the first time in the institution's history, the faculty who had voluntarily participated in peer learning communities also received financial support to continue their work. This funding allowed the group to expand its faculty base into other STEM disciplines and to add components aimed at building teaching skills among undergraduate STEM majors.

It would appear that this case study is an example of a successful model of faculty leadership, however in spite of these positive outcomes, some faculty participants felt that campus leaders viewed their work with the grant as a low priority relative to other faculty roles and responsibilities. In this institution, the faculty culture was competing with the aspirational goals of the administrative leadership, which had shifted ground, and began rewarding research over teaching in an attempt to "move up" in classification status. During the first three years of the grant-funded project, the campus leadership was determined to raise the prestige of the institution by increasing research productivity. One unfortunate consequence of this conflict between the faculty culture and the administrative culture was that one of the most engaged faculty members was denied tenure, in part, because of her heavy investment in the teaching/learning community. At the end of the third year of the project, a new provost was put in place, and the faculty learning community regained some of its standing.

This observation, that informal communities of reformminded faculty interested in improving the teaching and learning environments on campus are subject to the priorities and values of higher level administrators, appears to be a recurring theme of this research. Without support from institutional administration, even self-sustaining communities of faculty are often marginalized, and struggle to sustain their focus over time. University administrators need to be made aware of the tremendous influence they can have in fostering faculty grassroots leadership that makes positive contributions to the institution.

In this particular case, because the faculty learning community had been in place for several years prior to the grant and because it included tenured faculty members, it was able to weather the changing priorities of the administration, and accomplished several tangible outcomes, including new and revised courses. Like a "sponge," this faculty learning community was able to "morph" over time-absorbing external resources when they became available, expanding its existing capacity to include additional colleagues, and changing its form to accommodate emerging priorities. At the same time, since this group has always existed outside of the formal hierarchy and structure of the institution, the participants themselves have questioned the extent to which their efforts have been valued and recognized by the broader campus community. One role of an external funder (in this case, NSF), is to raise the level of public recognition for such work so that the institution can derive prestige from this important faculty work in teaching and learning, as well as the expansion of its research agenda.

\section{The "Magnet"}

The third case involves a public research university, classified by Carnegie as having a high level of research activity (institution C), in which top-level campus leaders and administrators had increasingly placed priority on educational partnerships and teaching reforms, particularly in the STEM disciplines. Despite this top-level support (president and provost), relatively few STEM faculty on this campus seemed to have an interest in becoming involved in the MSP partnership. The original leadership for the project was housed in the university's education department, which ultimately proved problematic for fully engaging STEM faculty. Initially, only one STEM faculty member was recruited-a biology professor with leadership experience in educational partnerships and teaching and learning reforms.

It became clear that a leader with stronger connections to the target faculty was needed, and after two years the NSF project landed in a very unlikely home-the university's community outreach and service-learning center. This outreach center has been a magnet for faculty, students, and administrators who want to do community service with public schools and various nonprofit organizations. It is an endowed center that also regularly receives external funding, so faculty are used to receiving notices that new projects are underway. In some ways, the center serves as a clearinghouse for bringing together various opportunities for community engagement, and any faculty and students who have the inclination to do community service. The center is a high functioning organization with great visibility on campus, and placing the grant-funded project in this new context provided the "magnet" that was needed to attract the attention of those grassroots faculty who are motivated to reach across boundaries.

This case is an interesting example of why it is important to allow for institutional context to inform decision-making around faculty grassroots leadership. One assumption underlying faculty grassroots leadership is that tenured faculty who have strong ties to departments are "safer" in exercising faculty leadership than others on campus. If nothing else, tenure allows faculty a degree of self-determination and frees them from the overwhelming pressure to earn tenure. This institution is the exception that proves the rule. At a university that has made a name for itself nationally and internationally as a socially-engaged institution, a center that exists outside the academic sphere of influence creates an environment where faculty of all ranks can feel free to enter and participate, finding like-minded colleagues outside their own departments. In this case, the center director invited faculty and high school teachers to participate in a discussion about ideas for their involvement. What evolved out of these initial efforts were several self-designed mini-projects among faculty and teachers who shared similar goals and interests.

Several faculty worked on designing and revising their undergraduate courses, including, for example, a special recitation section of a biology course, and a comprehensive reform of the introductory sequence in chemistry. Others extended their revision of curricula to include direct connections with high school teachers-by enlisting teacher expertise in the course revision process, by developing lesson plans to be piloted or used by teachers. In a unique and remarkably successful turn of events, the connections between teachers and faculty led to college students being invited into schools to do demonstrations, and high school students being invited to campus to participate in classes. The attraction of faculty, teachers, and students to the project would not have taken place had the project remained on the main campus in a department. The faculty leadership that emerged-invitations to exchange resources, students, and time - was a product of a uniquely situated center that had independent credibility, outside the traditional faculty sphere of influence.

The center hosted symposia for participating faculty and 
students which addressed the challenges that students face in their transition from high school science courses to collegelevel science courses. More specifically, these discussions led to the development of a new student fellowship component of the MSP, in which STEM majors were placed in high school classrooms to share their disciplinary research in order to expose high school students to examples of other students "doing science" and to encourage them to think about pursuing science as a college major.

In addition to their individual work and their work with high school teachers, several faculty at this institution also collaborated with each other across the disciplines. Faculty members in the mathematics and physics departments worked together on the infusion of inquiry into the training of STEM teaching assistants. When these faculty were invited by their dean to serve on a steering committee to design a college-wide training program for all teaching assistants. In this instance, what began as a grassroots-level initiative on the part of the faculty-who were working outside of their traditional roles and departmental boundaries-evolved into a program that was recognized as valuable enough by the academic leadership to bring to scale and institutionalize.

\section{The "Pied Piper"}

The fourth case occurred at a public flagship research university (institution D), classified by Carnegie as having a very high level of research activity, where traditional priorities of research, publications, and external funding shape the premier recognition and rewards structure for faculty. This was another case where the contextual home of the project proved to be problematic. The original leadership for the project was housed in the university's Center for Teaching and Learning, a somewhat independent center that did not have departmental affiliation, and ultimately proved problematic for fully engaging STEM faculty.

Initially, the grant-funded faculty project leader on campus tried to generate interest among STEM faculty by offering stipends and inviting them to join learning communities with fellow faculty colleagues and high school science teachers. Despite these enticements-and after months of communicating with deans, department chairs, and individual faculty members-it was clear that there was almost no interest in this work. At the same time, however, the university's president and provost were visible supporters of increasing institutional commitment to STEM education, including the production of more STEM majors and teachers. It was ultimately the faculty project leader who observed that given the existing culture in the STEM disciplines, even if faculty were interested in the goals of an educational partnership, they would be very unlikely to get involved unless it was directly grounded in their disciplinary research or teaching. In short, faculty did not seem to be responsive to STEM education initiatives that fell outside of the parameters of their traditional rewards structure.

The program languished for two years. Only one or two STEM faculty members participated in any of the school-university partnership activities, and even those did it as a personal favor to the project manager. It became clear that for this project to take root at this campus, an administrative home needed to emerge, where faculty could envision some sustainable support. The research culture was so strong at this institution, that faculty leaders instinctively knew that the program had to be incorporated into the campus strategic plan, if faculty participants were to receive any encouragement or reward.

Finally, in the fifth year of the grant, the associate provost invited a nationally respected physics professor (and former chair of the faculty senate) to assemble a group of trusted colleagues to discuss in earnest a campus-level agenda for reforming undergraduate science education. At the conclusion of this initial meeting, the associate provost asked the faculty if they wanted to continue to meet themselves, and was pleasantly surprised when they said yes! Eventually the group, which grew of its own accord to 16 faculty members, met for the rest of the year on a regular basis, led by the physics professor.

The outcome of the faculty led curricular reform was a series of six new interdisciplinary core courses for non-science majors, aimed at exposing students to contemporary world issues and improving their understanding of and appreciation for the science behind these issues. Addressing such topics as weather and climate, biogenesis, and global energy, these courses were first taught the following academic year and continue to be offered as one of the signature programs at this university.

In this example, it took several false starts before a successful mechanism for faculty leadership was discovered-ultimately in the form of one particularly important individual who brought personal credibility and passion to the project. In this respect, the "pied piper's" accomplishments far exceeded original expectations. By virtue of his significant personal and professional reputation, he generated an unexpected level of active, intellectual faculty involvement in various aspects of teaching and learning that fell outside of their regular reward structure. The institutionalized outcome was the development of a set of highly regarded and visible courses by an influential group of faculty leaders who may not have come together otherwise. Many of these faculty members continue to meet regularly to evaluate the ongoing implementation and impact of these courses.

\section{Discussion}

This paper describes an externally funded partnership project that depended on faculty grassroots leadership for successful implementation and ultimate sustainability. This was a high stakes project, given that NSF has invested over $\$ 600$ million to date in creating school-university partnerships to improve teaching and learning, and that future funding from NSF to all these institutions depended on successful implementation of the project goals. It became clear early into the project that simply offering incentive stipends or course buy-outs would not be enough to engage faculty. This study reinforces that while there are some common characteristics among faculty leaders, nurturing grassroots leadership is as much a function of campus context and culture as it is of individual motivation.

The four case studies illustrate four different models of emerging faculty leadership, and offer insights into four inter-related variables: faculty leadership, the role of top-down (administrative) support, the role of institutional context, and the dependent variable of culture change for sustainability.

While faculty leaders exist on every campus, our findings suggest that they are influenced both by campus culture and the degree of support or involvement from higher levels of administration. At institution B, the "sponge" model, faculty had preexisting, self-actualized learning communities that did not need support from the administration, on the face of it. These grassroots faculty had discovered the value of collaboration, and 
while the infusion of funding from the grant allowed them to expand their reach, it did not change the culture of the institution. In fact, at a time of transition (with campus leadership trying to raise the research profile) these faculty leaders stayed the course and managed to "outlast" the administrative pressure to alter their mission.

In contrast, campus A, the "catalyst," had no real source of faculty leadership at the institution. A community college, with a large percentage of part-time and adjunct instructors who only come to campus to teach classes, is an unlikely place to find faculty grassroots leadership. Yet by a judicious placement of a catalyst - a new hire whose sole responsibility was to build faculty learning communities that would lead to the necessary outcomes for the project (revised courses and curriculum, professional development in teaching and learning, and outreach to public schools), the higher level administrators provided the necessary starting point for those faculty who were motivated, but had no way of establishing a critical mass to join together and make progress toward the grant goals.

This raises the important question of the role of top down leadership support. It was quite clear that at the research universities, such support was necessary but not sufficient to encourage and nurture faculty leaders. At campus C, the "magnet," grassroots faculty could self-identify and join the project by attaching themselves to an existing campus structure-the Center for Community Service and Outreach. When the project was initially launched in the education department, there was no way to reach across the disciplinary boundaries to seek out like-minded faculty participants. However, when the project was relocated to a non-academic center, on this campus, it was hugely successful.

In contrast, at the second research university (institution D), placing the project in a non-academic center (Center for Teaching and Learning) completely marginalized the project. It took the personal charisma of one person, one "pied piper" to give the project credibility and attract new faculty members. This demonstrated that while there was untapped interest on the campus, faculty grassroots leaders - those potential risk takers - needed the extra motivation of seeing one of their most respected peers accepting the challenge of course reform around pedagogical outcomes, which had been simmering among many faculty members but always beneath the surface, overshadowed by the research priorities of the university.

These four colleges and universities varied significantly with respect to institutional missions, priorities, teaching loads, rewards systems, and culture. Examining the emergence of faculty grassroots leadership within the varied institutional contexts offers some insights into ways of encouraging such emerging leadership. Where institutions with strong faculty independence (institutions C and D) required a somewhat "light" administrative intervention, the community college required a more substantial administrative intervention. Once that occurred, however, it paved the way for a very productive and faculty-led curricular reform of the sort that was expected by the funders. Similarly, where faculty culture is strongest, grassroots leadership needs to be situated in a way that the most vulnerable faculty (untenured assistant professors, for example) can find some shelter for their initial advances into faculty leadership roles. Thus, at institution C, the "magnet" institution, allowing faculty to find like-minded peers at a well-regarded campus center was all that was necessary to link more than a dozen faculty members who had never worked together before, and launch a new, sustainable program of outreach to the public schools.

What factors accounted for these varying outcomes across the partnership? The authors contend that faculty grassroots leadership emerges on different campuses when there is sensitivity to the contextual differences. Rather than dismiss out of hand the role that high-level administration can play in encouraging faculty grassroots leadership, some attention needs to be given to the campus culture and the nature of faculty interactions at that site. The context for change at each institution and the role of administrative leadership and support shaped the conditions under which faculty grassroots leadership had emerged and, ultimately, the degree to which it was sustained over time. Table 1 summarizes the interplay among these factors in each of the four faculty grassroots leadership cases.

This grant-funded project depended on the emergence of faculty leadership to accomplish the goals and objectives of redesigned courses, inquiry oriented pedagogy, and outreach to public schools. Yet, the authors discovered that there was no single magic bullet that would impart the desired effect on at all the institutions in the same way. The faculty ownership of this project was essential to the success of the project, because, ultimately, the faculty needed to embrace the goals of curricular redesign and inquiry oriented pedagogy. Those cannot be "force fed" and be successful. Therefore, as part of the learning that occurred over the course of the five-year project, significant attention was paid to the emergence of faculty grassroots leadership and ownership of the innovations. Only by faculty leadership would the desired institutional changes become sustainable.

\section{Conclusion}

A key objective of NSF's MSP program was to promote institutional changes that resulted in recognizing and rewarding faculty leadership for work with K-12 schools and STEM education reform, which tend to be among the most under-appreciated roles in which higher education faculty typically engage. It is much more reasonable to expect faculty to lead reform efforts related to the curriculum or shared governance policies - that grassroots leadership in these areas would grow out of understandable self-interest and would be legitimized as part of their roles as faculty members. How much more difficult is it to recognize and reward faculty grassroots leadership in an area that is typically undervalued on a college or university campus? It should come as no surprise that there are disincentives for even the most motivated faculty to participate in such work. As Freeman Hrabowski, president of the University of Maryland, Baltimore County (UMBC), stated in his keynote remarks at the annual MSP Learning Network Meeting in 2007: “A major challenge to promoting faculty participation in P-16 work is that the higher education community at large tends not to see the work of involvement with K-12 as intellectually respectable or important enough to be considered part of the reward system" (NSF, 2007).

Ultimately, while all of the institutions in the present study sought to involve STEM faculty in innovative educational partnerships and to help build capacity for engaging in STEM education reform, faculty grassroots leadership evolved differently in each of the four cases. When considered as a single entity, higher education faculty can be seen as reflecting a common set of values and priorities-laboratory scientists in the disciplines have their own rules, rewards, and pathways to 
Table 1.

Four faculty grassroots leadership cases.

\begin{tabular}{|c|c|c|c|c|}
\hline & \multicolumn{4}{|c|}{ Institution } \\
\hline & $\begin{array}{l}\text { The Catalyst } \\
\text { (Community College) }\end{array}$ & $\begin{array}{c}\text { The Sponge } \\
\text { (Master's Level University) }\end{array}$ & $\begin{array}{l}\text { The Magnet } \\
\text { (Research University) }\end{array}$ & $\begin{array}{l}\text { The Pied Piper } \\
\text { (Research University) }\end{array}$ \\
\hline $\begin{array}{l}\text { Context for } \\
\text { Change }\end{array}$ & $\begin{array}{l}\text { Aligned with Institutional Mission and } \\
\text { Priorities; Workload Initially Precluded } \\
\text { Faculty Leadership and Involvement }\end{array}$ & $\begin{array}{c}\text { High Degree of Faculty Interest and } \\
\text { Alignment with Existing Reform } \\
\text { Efforts; Already } \\
\text { Positioned Outside of Formal } \\
\text { Campus Hierarchy }\end{array}$ & $\begin{array}{l}\text { Visible Leadership Support } \\
\text { but Incongruent with } \\
\text { Existing Rewards } \\
\text { Structures; Low Faculty } \\
\text { Interest Initially }\end{array}$ & $\begin{array}{l}\text { Visible Leadership Support } \\
\text { but Incongruent with } \\
\text { Existing Rewards } \\
\text { Structures; Low Faculty } \\
\text { Interest Initially }\end{array}$ \\
\hline $\begin{array}{l}\text { Role of Campus } \\
\text { Administrative } \\
\text { Leadership }\end{array}$ & Dean Level Initiated & Faculty Level Initiated & $\begin{array}{l}\text { Associate Provost } \\
\text { Level Initiated }\end{array}$ & $\begin{array}{l}\text { Associate Provost Level } \\
\text { Initiated }\end{array}$ \\
\hline $\begin{array}{l}\text { Emergence of } \\
\text { Faculty Grassroots } \\
\text { Leadership }\end{array}$ & $\begin{array}{l}\text { Facilitated by External } \\
\text { Faculty Change Agent }\end{array}$ & $\begin{array}{l}\text { Developed in the Context } \\
\text { of an Existing Faculty Group }\end{array}$ & $\begin{array}{l}\text { Developed in the Context of a } \\
\text { Newly Created Faculty Group } \\
\text { through an Existing } \\
\text { Institutional Structure }\end{array}$ & $\begin{array}{l}\text { Facilitated by Internal } \\
\text { Faculty Change Agent }\end{array}$ \\
\hline $\begin{array}{l}\text { Institutionalization } \\
\text { and Sustainability }\end{array}$ & $\begin{array}{l}\text { New and Reformed } \\
\text { Undergraduate Science Courses; } \\
\text { Faculty Learning Community }\end{array}$ & $\begin{array}{l}\text { New and Reformed } \\
\text { Undergraduate Science Courses; } \\
\text { Faculty Learning Community }\end{array}$ & $\begin{array}{l}\text { New and Reformed } \\
\text { Undergraduate Science } \\
\text { Courses; Teaching Assistant } \\
\text { Training Program; Student } \\
\text { Fellowship Program }\end{array}$ & $\begin{array}{l}\text { New Sequence of } \\
\text { Undergraduate Courses for } \\
\text { Non-Science Majors }\end{array}$ \\
\hline
\end{tabular}

success, for example. Introducing new priorities (in this case, the broader public policy arena of STEM education reform) will motivate individual faculty differently, depending on their priorities and interests, but also depending on the organizational supports and incentives that are in place. When considered in this light, one of the major roles of the broader partnership in this study was to test support for these changes in higher education at the organizational (i.e., college and university leadership) level. If colleges and universities truly value such efforts, then recognizing and rewarding faculty grassroots leadership is one way to help ensure that these faculty change agents will continue to reach the next generation of curious, engaged, and creative thinkers - both faculty and students - as a lasting legacy of their investments in STEM education reform.

\section{REFERENCES}

Burack, C., \& Saltmarsh, J. (2007). Advancing civic engagement through strategic assessment. Boston, MA: New England Resource Center for Higher Education.

Cohen, M. D., \& March, J. G. (1974). Leadership and ambiguity: The American college president. New York: McGraw-Hill.

Committee on Prospering in the Global Economy of the 21st Century: An Agenda for American Science and Technology, National Academy of Sciences, National Academy of Engineering, Institute of Medicine (2007). Rising above the gathering storm: Energizing and employing America for a brighter economic future. Washington DC: National Academies Press.

Eckel, P., \& Kezar, A. (2003). Taking the reins: Institutional transformation in higher education. Phoenix, AZ: ACE/ORYX Press.

Ewell, P. (1997). Organizing for learning: A point of entry. Snowbird, UT: Draft Prepared for Discussion at the American Association of Higher Education Summer Academy.

Fairweather, J. S. (2002). The ultimate faculty evaluation: Promotion and tenure decisions. New Directions for Institutional Research, 114, 97-108. doi:10.1002/ir.50

Frank, J., \& Shapiro, N. (2007). MSP Learning Network Conference Report: Engaging STEM faculty in MSP: Promises and challenges. http://hub.mspnet.org/index.cfm/14515

Frost, S. H., \& Teodorescu, D. (2001). Teaching excellence: How faculty guided change at a research university. Review of Higher Education, 24, 397-415. doi:10.1353/rhe.2001.0007
Ginsberg, A., \& Abrahamson, E. (1991). Champions of change and strategic shifts: The role of internal and external change agents. Journal of Management Studies, 28, 173-190. doi:10.1111/j.1467-6486.1991.tb00276.x

Greenberg, R. (1991). High school-college partnerships: Conceptual models, programs, and issues. ASHE-ERIC Higher Education Report (No. 5), Washington DC: The George Washington University.

Handelsman, J., Ebert-May, D., Beichner, R., Bruns, P., Chang, A., DeHaan, R. et al. (2004). Scientific teaching. Science, 304, 521-522. doi:10.1126/science.1096022

Hearn, T. (2006). Leadership and teaching at the American university. In D. G. Brown (Ed.), University presidents as moral leaders. Westport, CT: Praeger.

Henderson, C., Beach, A., Finkelstein, N., \& Larson, R. S. (2008). Preliminary categorization of literature on promoting change in undergraduate STEM. In Proceedings of the Facilitating Change in Undergraduate STEM Symposium. Augusta, MI.

http://www.wmich.edu/science/facilitating-change/PreliminaryCateg orization.pdf

Kanter, R. M. (1988). When a thousand flowers bloom: Structural, collective, and social conditions for innovation in organization. Research in Organizational Behavior, 10, 169-211.

Kezar, A. (2001). Understanding and facilitating organizational change in the 21st century: Recent research and conceptualizations. Washington DC: ASHE-ERIC Higher Education Reports.

Kezar, A., \& Eckel, P. (2002). The effect of institutional culture on change strategies in higher education: Universal principles or culturally responsive concepts? Journal of Higher Education, 73, 435-460. doi:10.1353/jhe.2002.0038

Levine, A. (1980). Why innovation fails. Albany, NY: State University of New York Press.

Lewin, K. (1951). Field-theory in social science. NewYork: Harper and Row.

Merton, P., Froyd, J., Clark, M. C., \& Richardson, J. (2004). Challenging the norm in engineering education: Understanding organizational culture and curricular change. In Proceedings of the 2004 American Society for Engineering Education Annual Conference and Exposition (Session 2630).

National Science Foundation (2007). Engaging STEM faculty in MSP: Promises and challenges. In Transcript Proceedings from the 2007 Math and Science Partnership Learning Network Conference. http://hub.mspnet.org/index.cfm/14001

Neave, G. (1979). Academic drift: Some views from Europe. Studies in Higher Education, 4, 143-159. 
doi:10.1080/03075077912331376927

O’Meara, K. (2006). Encouraging multiple forms of scholarship in faculty reward systems: Have academic cultures really changed? New Directions for Institutional Research, 29, 77-95.

doi:10.1002/ir.173

Peck, R. D. (1983). The entrepreneurial college presidency. Educational Record, 18-25.

Schein, E. H. (1997). Organizational culture and leadership (2nd ed.). San Francisco: Jossey-Bass.

Timpane, P. M., \& White, L. S. (Eds.) (1998). Higher education and school reform. San Francisco, CA: Jossey-Bass.

Verbeke, K., \& Richards, P. O. (2001). School-university collaborations. Fastback 485, Bloomington, IN: Phi Delta Kappa Educational Foundation.
Wallace, J. (1993). Building bridges: A review of school-college partnership literature. Denver, CO: Education Commission of the States. Weick, K. E. (1976). Educational organizations as loosely coupled systems. Administrative Science Quarterly, 21, 1-19. doi: $10.2307 / 2391875$

Wiseman, D. L., \& Knight, S. L. (Eds.) (2003). Linking school-university collaboration and K-12 student outcomes. Washington DC: American Association of Colleges for Teacher Education.

Yin, R. K. (2002). Case study research: Design and methods (3rd ed.). Thousand Oaks, CA: Sage Publications, Inc.

Zhang, X., McInerney, J., Frechtling, J., Nyre, G., Michie, J., Miyaoka, A. et al. (2007). Effect of STEM faculty engagement in MSP: A longitudinal perspective. Rockville, MD: WESTAT. 